\title{
Methods of Hearing Preservation during Cochlear Implantation
}

\author{
Ahmed Khater ${ }^{1}$ Mohammad Waheed El-Anwar ${ }^{1}$ \\ ${ }^{1}$ Department of Otorhinolaryngology Head and Neck Surgery, Zagazig \\ University, Zagazig, Egypt \\ Int Arch Otorhinolaryngol 2017;21:297-301. \\ Address for correspondence Mohammad Waheed El-Anwar MD, \\ Department of Otorhinolaryngology Head and Neck Surgery, Zagazig \\ University, Zagazig 0020552309843, Egypt \\ (e-mail: mwenteg@yahoo.com; mwenteg1973@gmail.com).
}

\begin{abstract}
Keywords

Introduction Recent advances in surgical techniques and electrode design have made residual hearing preservation during cochlear implantation $(\mathrm{Cl})$ possible, achievable, and desirable.

Objectives The objective of this study was to review the literature regarding methods used for hearing preservation during $\mathrm{Cl}$ surgery.

Data Synthesis We performed a search in the LILACS, MEDLINE, SciELO, PubMed databases, and Cochrane Library, using the keywords $\mathrm{Cl}$, hearing preservation, $\mathrm{Cl}$ electrode design, and $\mathrm{Cl}$ soft surgery. We fully read about 15 studies that met the criteria described in "study selection". The studies showed that several factors could contribute to possible cochlear damage during or after $\mathrm{Cl}$ surgery and must be kept in mind; mechanical damage during electrode insertion, shock waves in the perilymph fluid due to implantation, acoustic trauma due to drilling, loss of perilymph and disruption of inner ear fluid homeostasis, potential bacterial infection, and secondary intracochlear fibrous tissue formation. The desire to preserve residual hearing has led to the development of the soft-surgery protocols with its various components; avoiding entry of blood into the cochlea and the use of hyaluronate seem to be reasonably supported, whereas the use of topical steroids is questionable. The site of entry into the cochlea, electrode design, and the depth of insertion are also important contributing factors.

- cochlear implantation

Conclusion Hearing preservation would be useful for $\mathrm{Cl}$ patients to benefit from the

- ear

- hearing residual low frequency, as well as for the children who could be candidate for future regenerative hair cell therapy.
\end{abstract}

\section{Introduction}

Cochlear implants (Cls) represent a well-established treatment for severe and profound bilateral hearing loss. The number of candidates with significant residual hearing who are eligible to receive Cls has increased, fostering studies on attempts of preservation of the residual hearing in these patients. ${ }^{1}$ Hearing preservation is essential for all $\mathrm{CI}$ recipients for several reasons. ${ }^{2,3}$ First, because it helps to ensure that some neural structures in the cochlea are left undamaged, which is critical

received

March 24, 2016

accepted

June 3, 2016

published online

July 12, 2016 10.1055/s-0036-1585094. ISSN 1809-9777. in allowing $\mathrm{Cl}$ recipients to benefit from future therapies and/or technologies. It is likely that any future interventions, either device, biological, or pharmaceutical in nature, will be more successful in attaining a cochlea with preserved neural structures. Second, many individuals with severe to profound hearing loss may still be able to hear some low frequency sounds. Preservation of the residual hearing during $\mathrm{Cl}$ surgery is vitally important, as it enables the patients to use the natural hearing in combination with a CI, providing the user with the best possible listening experience. ${ }^{1}$ Therefore, for all $\mathrm{CI}$ recipients, hearing
Copyright $\odot 2017$ by Thieme Revinter

Publicações Ltda, Rio de Janeiro, Brazil
License terms

(우(1) $\Theta \circledast$ 
preservation during a $\mathrm{Cl}$ procedure is essential for their hearing both now and in the future. Considering the importance of a good understanding of the factors that assist to a higher rate of hearing preservation in patients who undergo $\mathrm{Cl}$, this study aimed to review the literature regarding methods used for hearing preservation during $\mathrm{CI}$ surgery.

\section{Review of Literature}

We searched several medical databases, including LILACS, MEDLINE, SciELO, PubMed, and the Cochrane Library to find out relevant articles. We focused our review on studies involving how to preserve residual hearing during $\mathrm{CI}$. Following Miranda et $\mathrm{al}^{1}{ }^{1}$ several factors could contribute to possible cochlear damage during or after $\mathrm{CI}$ surgery. Most of them related to the surgical technique. The desire to preserve residual hearing has led to the development of the soft-surgery. The site of entry into the cochlea, electrode design, and the depth of insertion are also important contributing factors. The authors fully read and analyzed the results of 15 studies that describe various approaches to preserve residual hearing during $\mathrm{Cl}$, highlighting their importance for hearing preservation both now and in the future to profit from any new regenerative hair cell therapy.

\section{Discussion}

Intracochlear trauma by electrode insertion and foreign body reaction to the implanted electrode within the scala tympani might be sufficient to cause hearing loss. Hearing preservation during $\mathrm{CI}$ is based on five items; minimally invasive surgery, suitable route for insertion, gentle insertion technique, control of the inflammatory response to electrode insertion, and use of atraumatic electrode.

\section{Minimally Invasive Surgery}

The technique is based on a commonsense approach to open and manipulate the cochlea. Some of the principles of the soft-surgery technique are also dependent on early otology surgery experience and subsequent experience with $\mathrm{CI}$. The objectives of the soft-surgery technique include avoidance of mechanical trauma to the cochlea and reduction of the introduction of factors that may cause adverse intracochlear reactions. ${ }^{4,5}$ Care is taken during the approach to the cochlea to minimize the potential for acoustic trauma such as from micro drill contact with the ossicular chain. ${ }^{6}$ Bone dust and pate are thoroughly irrigated away to avoid their entry into the cochlea at the cochleostomy or by contact with the electrode array. Because blood is an inner-ear toxin, its entry into the cochlea should be also avoided by preparing the tympanic cavity to minimize bleeding and decrease the potential for blood to enter the cochlea. ${ }^{7}$ Postulated mechanisms for the hearing loss as mentioned by Radeloff et $\mathrm{al}^{8}$ included oxidative damage induced by hemoglobin or inflammatory reaction to blood and its breakdown products, as well as additional fluid introduction into the cochlea.

Loss of perilymph from the inner ear can have detrimental effects on cochlea-vestibular function. Gentle perilymph exposure may be quite safe. ${ }^{9}$ However, the surgeon must take cautions against the suctioning of perilymph with additional concerns of the suction tip that can cause mechanical damage to the basilar membrane and osseous spiral lamina. ${ }^{4}$ Moreover, the surgeon should make sure to permit the escape of excess perilymph out of the cochlea to prevent its effect on the endocochlear potential.

\section{Suitable Electrode Insertion Route}

$\mathrm{CI}$ arrays can be inserted through the round window (RW) or via cochleostomy. The RW insertion has been referred to as a less traumatic and more direct approach to the scala tympani than cochleostomy. ${ }^{3}$

- Table 1 gathers results of clinical human studies comparing the RW versus the cochleostomy approach, showing that RW approach causes the same $\mathrm{e}^{10,11}$ or significantly less trauma to the cochlea. ${ }^{12,13}$

Table 1 Results of clinical studies compared round widow (RW) versus cochleostomy approach in Cl

\begin{tabular}{|c|c|c|c|}
\hline Results & Device used & Number of patients & Study \\
\hline $\begin{array}{l}\text { Greater significant damage occurred in } \\
\text { cochleostomy and RWE groups than in RW }\end{array}$ & $\mathrm{N} / \mathrm{A}$ & $\begin{array}{l}\text { 12; } 3 \text { groups of temporal bones: } \\
\text { insertion through RW, after enlarging } \\
\text { RW (RWE) and cochleostomy }\end{array}$ & Richard et al ${ }^{12}$ \\
\hline no statistically significant differences & $\mathrm{N} / \mathrm{A}$ & $\begin{array}{l}20 ; 8(40 \%) \text { round window-related } \\
\text { cochleostomy and } 12(60 \%) \text { RW }\end{array}$ & Adunka et al ${ }^{10}$ \\
\hline no statistically significant difference & $\begin{array}{l}\text { Cochlear Nucleus } \\
\mathrm{Cl} 422 \text { slim } \\
\text { straight electrode }\end{array}$ & $41 ; 14$ cochleostomy & \\
\hline 27 RW approach. & Hassepass et al ${ }^{11}$ & & \\
\hline $\begin{array}{l}\text { RW was less harmful to residual hearing } \\
\text { particularly at } 125 \mathrm{~Hz}(p<0.05) \text {, than stan- } \\
\text { dard cochleostomy }\end{array}$ & Med-El +Flex (SOFT) & 34; 17 RW-HP with full insertion & \\
\hline $\begin{array}{l}-17 \text { cochleostomy with shorter perimodiolar } \\
\text { electrodes. }\end{array}$ & Nordfalk et al ${ }^{13}$ & & \\
\hline
\end{tabular}

Abbreviations: $\mathrm{Cl}$, cochlear implantation; RW, round window; RWE, enlarged round window. 
Cochleostomy is the traditional and more commonly used approach to the scala tympani. Cochleostomy site and size have a role in hearing preservation and so avoiding damage to inner ear structures. Cochleostomy located anterior-inferior to the RW membrane is the preferred site because it is correlated with better residual hearing results than a strictly inferior or anterior entry. ${ }^{14}$ This site avoids damage to the osseous spiral lamina and so inadvertent entry into the scala media or scala vestibuli. ${ }^{15,16}$ A small cochleostomy enabled Sharzynski et al ${ }^{17}$ to preserve some hearing in 21 of their 26 patients (80.8\%) using the soft-surgery technique.

Lenarz et $\mathrm{al}^{18}$ found that RW insertion may not be suitable for all electrode configurations. Longer, thicker and less flexible electrodes insertion through RW became difficult and required cochleostomy. Thinner and more flexible electrodes have enabled insertion through RW. When using a custom short array, RW produces little intracochlear damage. However, using a perimodiolar electrode showed significant damage to basal turn structures.

There is no accurate evidence determining the best method for hearing preservation $\mathrm{CI}$. Initially, insertion through the RW was the standard technique for hearing preservation $\mathrm{CI}$ surgery. This technique consists of a minimal incision through the membrane, with no need for drilling the cochlea, thereby reducing acoustic trauma and the possibility of bone fragments entering the scala tympani. ${ }^{3}$ However, a recently published study showed that the angle of insertion of the electrode is similar for both techniques (through the RW and by cochleostomy), and in both procedures, tissue damage will be minimal if an electrode designed for hearing protection is used. ${ }^{19}$ In a systematic literature review in 2013 comparing the two approaches, we could not find a single study specifically comparing insertion techniques; the levels of hearing preservation were similar between the two approaches, being slightly higher in patients undergoing insertion through the RW. ${ }^{3}$

The cochleostomy approach is familiar to nearly all $\mathrm{CI}$ surgeons; nonetheless, it needs to be placed appropriately. Meanwhile, Adunka et $\mathrm{al}^{10}$ reported that the RW approach demonstrates an advantage over cochleostomy in hearing preservation and explained this by known potential problems with cochleostomy, such as (a) perilymph loss and acoustic trauma caused by drilling; (b) formation of new bone within the cochlea, caused by the presence of bone dust; (c) the risk of osseous spiral lamina injury; and (d) damage due to infection, which may cause the formation of fibrous tissue. Temporal bone studies were used to address these issues and have demonstrated the supremacy of the RW approach over cochleostomy in preventing trauma to cochlear structures as mentioned by Adunka et al. ${ }^{10}$

\section{Gentle Insertion Technique}

The introduction of the electrode array into the cochlea certainly plays an important role in hearing preservation. To decrease insertion force, a drop of surgical lubricant such as hyaluronic acid could be applied into the opened endosteum. Every efforts should be done to avoid any forceful procedure and the insertion should be stopped at the first resistance point. Surgeons have to be aware of the electrode insertion force and speed, keeping it slow and steady as force equals trauma. The insertion is performed with as little pressure as possible. Resistance may indicate contact of the electrode tip with the basilar membrane, osseous spiral lamina, or vasculature along the lateral cochlea wall ${ }^{20,21}$ (-Table 2).

The electrode array can be coated in steroid or Healon to provide lubrication and easier insertion. Healon ${ }^{\circledR}$ (sodium hyaluronate, a.k.a. hyaluronic acid or hyaluronan) is a normal constituent of the extracellular matrix. It is commonly used in implant surgery as a lubricant for electrode insertion. ${ }^{22}$ Secondary to cytostatic properties of the hyaluronate, it can reduce friction and trauma during electrode placement, prevent perilymph leakage, and/or prevent cochlea contamination with blood and bone dust. Despite these favorable outcomes, there is some indication that gross introduction of hyaluronic acid into the cochlea may have cytotoxic effects and should be avoided in hearing preservation surgery.

\section{Control Inflammatory Reaction after CI}

Despite meticulous surgical technique, opening of the cochlea and placement of a foreign body within the scala tympani will elicit cellular and molecular responses. Cochlear implantation is always accompanied by surgical injury, which initiates an

Table 2 Results of studies investigating the $\mathrm{Cl}$ insertion forces

\begin{tabular}{|l|l|}
\hline Study & Results and recommendation \\
\hline Kontorinis et al $^{20}$ & $\begin{array}{l}\text { High insertion speeds significantly increase insertion; thus, during the insertion, Cl surgeons should use low } \\
\text { and stable speeds. On experimental models, insertion speed close to the average used value in the theaters } \\
\text { should be utilized to approximate human Cl conditions. }\end{array}$ \\
\hline${\text { Radeloff et } \mathrm{al}^{8}}^{8}$ & $\begin{array}{l}\text { Coating of the Cl electrode carrier may decrease insertion forces leading to less surgical trauma. Coating may } \\
\text { assist to transmit and deliver drugs to the apical parts of the cochlear, where there are hair cells reside in } \\
\text { patients with residual hearing }\end{array}$ \\
\hline Anagiotos et al ${ }^{21}$ & $\begin{array}{l}\text { During Cl, the underwater technique provides a reliable non-traumatic method for insertion of the electrode } \\
\text { array because it respects the cochlear physiology and minimizes the pressure changes during cochlear } \\
\text { opening and implantation. }\end{array}$ \\
\hline
\end{tabular}

Abbreviations: $\mathrm{Cl}$, cochlear implantation; RW, round window. 
acute inflammatory response to the electrode. The acute phase of inflammation may be replaced by a chronic phase due to a foreign body reaction induced by components of the electrode array. Seyyedi and $\mathrm{Nadol}^{23}$ reported that the severity of the fibrotic reaction and new bone formation adjacent to the intracochlear part of the electrode was significantly more apparent at the cochleostomy compared with the middle and the tip of the electrode. Fibrosis along the basal turn is predicted to alter vibration of the apical basilar membrane and, thus, interfere with residual low-frequency acoustic hearing. ${ }^{24}$

There is the concept that applying steroids directly on the round window, cochleostomy site, and/or the electrode array can inhibit inflammatory and molecular responses to implantation and avoid the loss of residual hearing with strong evidence that steroids can protect the cochlea from adverse reaction to cochleostomy and electrode insertion. Freidland et $\mathrm{al}^{25}$ reported that the protective effect, however, was only seen with intrascalar administration of the steroid. Furthermore, when a steroid is applied topically, it reaches peak concentration within an hour and lasts less than 24 hours. ${ }^{26}$ Systemic steroid use, however, may provide the necessary dosage and duration of treatment to protect the cochlea. The aim of postoperative medication is to prevent against long term intracochlear cell death. Intravenous corticosteroids should be used to prevent or limit apoptosis of functional cells. Additionally, postoperative antibiotics should be used to avoid infection which could compromise residual cochlear function.

\section{Atraumatic Electrodes}

There are variety of $\mathrm{Cl}$ electrodes; surgeons and audiologists can work together to select the perfect individualized electrode for a patient. There is no one electrode that is suitable to all candidates. Despite successful preservation of low frequency hearing in patients undergoing $\mathrm{CI}$, there remains controversy over which devices should be used to maximize hearing preservation. ${ }^{27}$ Although shorter electrodes may minimize trauma to the apical cochlea, they may fail to electrically stimulate the distal cochlear neurons in some with a longer duration of high-frequency hearing loss. This may result in poor performance. ${ }^{28}$ Therefore, investigators are actively searching for an electrode that maximizes acoustic potential without compromising electric potential.

Looking at the cochlear duct length on the preoperative CT scan as well as preoperative audiological assessment can be valuable guide in electrode selection as can identifying how much hearing there is to preserve. Long, medium, and short electrodes are all options. Both standard and atraumatic electrodes are available. The standard electrode is what we would consider for the conventional cochlear implant recipient.

For an atraumatic insertion, electrodes with special characters should be used. The tip of the electrode plays an important role in hearing preservation as it can fit through a round window or a tiny cochleostomy. Flexibility of the electrode is another option. To increase flexibility of the electrode in one design, the five most apical contacts are not paired, through which the diameter at the tip is oval to provide better apical flexibility. Slim electrodes have been found to be less invasive. Half band electrodes are designed to ensure that the electrodes are as thin as possible. Realistically, a flexible electrode with thin tapering tip and very short diameter can easily fit through a round window or small cochleostomy. ${ }^{29}$

\section{Final Comments}

Although still not conclusively proven, most agree that minimizing trauma during $\mathrm{CI}$ electrode insertion will result in improved audiological performance. ${ }^{30}$ Gantz et $\mathrm{al}^{31}$ have shown that preserving acoustic hearing offers advantages in back-ground noise and music appreciation. Carlson et $\mathrm{al}^{2}$ found that patients with hearing preservation had significantly better postoperative speech-perception performance in the Cl-only condition compared with those who lost residual hearing. Gifford et $\mathrm{al}^{30}$ showed that $\mathrm{Cl}$ with hearing preservation yields significant benefit for speech recognition in complex listening environments. As such, extensive effort has been focused on minimizing the identified mechanisms of mechanical trauma during electrode insertion including fracture of the osseous spiral lamina, injury to the modiolus, compression or tearing of vasculature, and interscalar excursion from scala tympani to scala vestibule. ${ }^{31,32}$

In our opinion, experience of the surgeon with skilled hands, as well as type of the electrode implanted, play a major role in hearing preservation through atraumatic soft surgery procedure.

\section{Conflict of Interest and Financial Support}

The authors declare no conflict of interest or financial support or interest to this study.

\section{References}

1 Miranda PC, Sampaio AL, Lopes RA, Ramos Venosa A, de Oliveira CA. Hearing preservation in cochlear implant surgery. Int J Otolaryngol 2014;2014:468515

2 Carlson ML, Driscoll CL, Gifford RH, et al. Implications of minimizing trauma during conventional cochlear implantation. Otol Neurotol 2011;32(6):962-968

3 Havenith S, Lammers MJ, Tange RA, et al. Hearing preservation surgery: cochleostomy or round window approach? A systematic review. Otol Neurotol 2013;34(4):667-674

4 Cohen NL. Cochlear implant soft surgery: fact or fantasy? Otolaryngol Head Neck Surg 1997;117(3 Pt 1):214-216

5 Eshraghi AA, He J, Mou CH, et al. D-JNKI-1 treatment prevents the progression of hearing loss in a model of cochlear implantation trauma. Otol Neurotol 2006;27(4):504-511

6 Pau HW, Just T, Bornitz M, Lasurashvilli N, Zahnert T. Noise exposure of the inner ear during drilling a cochleostomy for cochlear implantation. Laryngoscope 2007;117(3):535-540

7 Franco-Vidal V, Songu M, Blanchet H, Barreau X, Darrouzet V. Intracochlear hemorrhage after gamma knife radiosurgery. Otol Neurotol 2007;28(2):240-244

8 Radeloff A, Unkelbach $\mathrm{MH}$, Tillein J, et al. Impact of intrascalar blood on hearing. Laryngoscope 2007;117(1):58-62

9 Hara M, Nomura Y, Saito K. Histopathologic study of the perilymph-suctioned labyrinth. Ann Otol Rhinol Laryngol 1990;99 (4 Pt 1):316-320 
10 Adunka O, Unkelbach MH, Mack M, Hambek M, Gstoettner W, Kiefer J. Cochlear implantation via the round window membrane minimizes trauma to cochlear structures: a histologically controlled insertion study. Acta Otolaryngol 2004;124(7):807-812

11 Hassepass F, Aschendorff A, Bulla S, et al. Radiologic Results and Hearing Preservation With a Straight Narrow Electrode via Round Window Versus Cochleostomy Approach at Initial Activation. Otol Neurotol 2015;36(6):993-1000

12 Richard C, Fayad JN, Doherty J, Linthicum FH Jr. Round window versus cochleostomy technique in cochlear implantation: histologic findings. Otol Neurotol 2012;33(7):1181-1187

13 Nordfalk KF, Rasmussen K, Bunne M, Jablonski GE. Deep round window insertion versus standard approach in cochlear implant surgery. Eur Arch Otorhinolaryngol 2016;273(1):43-50

14 Garcia-Ibanez LM, Acias AR, Morera C, et al. An evaluation of the preservation of residual hearing with the Nucleus(R) Contour Advance trade mark electrode. Acta Otolaryngol 2008;129(6):1-14

15 Briggs RJ, Tykocinski M, Stidham K, Roberson JB. Cochleostomy site: implications for electrode placement and hearing preservation. Acta Otolaryngol 2005;125(8):870-876

16 Skarzynski H, Lorens A, Piotrowska A, Anderson I. Preservation of low frequency hearing in partial deafness cochlear implantation (PDCI) using the round window surgical approach. Acta Otolaryngol 2007;127(1):41-48

17 Skarzyński H, Lorens A, D'Haese P, et al. Preservation of residual hearing in children and post-lingually deafened adults after cochlear implantation: an initial study. ORL J Otorhinolaryngol Relat Spec 2002;64(4):247-253

18 Lenarz T, Stöver T, Buechner A, et al. Temporal bone results and hearing preservation with a new straight electrode. Audiol Neurootol 2006;11(1, Suppl 1):34-41

19 Briggs RJ, Tykocinski M, Xu J, et al. Comparison of round window and cochleostomy approaches with a prototype hearing preservation electrode. Audiol Neurootol 2006;11(Suppl 1):42-48

20 Kontorinis G, Lenarz T, Stöver T, Paasche G. Impact of the insertion speed of cochlear implant electrodes on the insertion forces. Otol Neurotol 2011;32(4):565-570
21 Anagiotos A, Beutner D, Gostian AO, Schwarz D, Luers JC, Hüttenbrink KB. Insertion of Cochlear Implant Electrode Array Using the Underwater Technique for Preserving Residual Hearing. Otol Neurotol 2016;37(4):339-344

22 Laszig R, Ridder GJ, Fradis M. Intracochlear insertion of electrodes using hyaluronic acid in cochlear implant surgery. J Laryngol Otol 2002;116(5):371-372

23 Seyyedi M, Nadol JB Jr. Intracochlear inflammatory response to cochlear implant electrodes in humans. Otol Neurotol 2014;35(9): 1545-1551

$24 \mathrm{Choi} \mathrm{CH}$, Oghalai JS. Predicting the effect of post-implant cochlear fibrosis on residual hearing. Hear Res 2005;205(1-2):193-200

25 Friedland DR, Runge-Samuelson C. Soft cochlear implantation: rationale for the surgical approach. Trends Amplif 2009;13(2): 124-138

26 Hargunani CA, Kempton JB, DeGagne JM, Trune DR. Intratympanic injection of dexamethasone: time course of inner ear distribution and conversion to its active form. Otol Neurotol 2006;27(4):564-569

27 Van Abel KM, Dunn CC, Sladen DP, et al. Hearing preservation among patients undergoing cochlear implantation. Otol Neurotol 2015;36(3):416-421

28 Mick P, Amoodi H, Shipp D, et al. Hearing preservation with full insertion of the FLEXsoft electrode. Otol Neurotol 2014;35(1): e40-e44

29 Wanna GB, Noble JH, Carlson ML, et al. Impact of electrode design and surgical approach on scalar location and cochlear implant outcomes. Laryngoscope 2014;124(6, Suppl 6):S1-S7

30 Gifford RH, Dorman MF, Skarzynski H, et al. Cochlear implantation with hearing preservation yields significant benefit for speech recognition in complex listening environments. Ear Hear 2013; 34(4):413-425

31 Gantz BJ, Turner C, Gfeller KE, Lowder MW. Preservation of hearing in cochlear implant surgery: advantages of combined electrical and acoustical speech processing. Laryngoscope 2005;115(5):796-802

32 Roland PS, Wright CG. Surgical aspects of cochlear implantation: mechanisms of insertional trauma. Adv Otorhinolaryngol 2006; 64:11-30 